\title{
Rituximab/Venetoclax Regimen
}

National Cancer Institute

\section{Source}

National Cancer Institute. Rituximab/Venetoclax Regimen. NCI Thesaurus. Code C160537.

A regimen consisting of rituximab and venetoclax that may be used in the treatment of relapsed or refractory chronic lymphocytic leukemia (CLL)/small lymphocytic lymphoma (SLL). 